\title{
Constitutive overexpression of soybean plasma membrane intrinsic protein GmPIP1;6 confers salt tolerance
}

Lian Zhou ${ }^{1,2+}$, Chuang Wang ${ }^{1 \dagger}$, Ruifang Liu', Qiang Han ${ }^{1}$, Rebecca K Vandeleur ${ }^{3}$, Juan Du' ${ }^{1}$, Steven Tyerman ${ }^{3}$ and Huixia Shou ${ }^{1 *}$

\begin{abstract}
Background: Under saline conditions, plant growth is depressed via osmotic stress and salt can accumulate in leaves leading to further depression of growth due to reduced photosynthesis and gas exchange. Aquaporins are proposed to have a major role in growth of plants via their impact on root water uptake and leaf gas exchange. In this study, soybean plasma membrane intrinsic protein 1;6 (GmPIP1;6) was constitutively overexpressed to evaluate the function of GmPIP1;6 in growth regulation and salt tolerance in soybean.

Results: GmPIP1;6 is highly expressed in roots as well as reproductive tissues and the protein targeted to the plasma membrane in onion epidermis. Treatment with $100 \mathrm{mM} \mathrm{NaCl}$ resulted in reduced expression initially, then after 3 days the expression was increased in root and leaves. The effects of constitutive overexpression of GmPIP1;6 in soybean was examined under normal and salt stress conditions. Overexpression in 2 independent lines resulted in enhanced leaf gas exchange, but not growth under normal conditions compared to wild type (WT). With 100 $\mathrm{mM} \mathrm{NaCl}$, net assimilation was much higher in the GmPIP1;6-Oe and growth was enhanced relative to WT. GmPIP1;6-Oe plants did not have higher root hydraulic conductance $\left(L_{0}\right)$ under normal conditions, but were able to maintain $L_{0}$ under saline conditions compared to WT which decreased $L_{0}$. GMPIP1;6-Oe lines grown in the field had increased yield resulting mainly from increased seed size.
\end{abstract}

Conclusions: The general impact of overexpression of GmPIP1;6 suggests that it may be a multifunctional aquaporin involved in root water transport, photosynthesis and seed loading. GmPIP1;6 is a valuable gene for genetic engineering to improve soybean yield and salt tolerance.

Keywords: Soybean, Aquaporins, Salt tolerance, Ovexpression, Transformation, GmPIP1;6

\section{Background}

A significant proportion of cultivated land is salt affected representing about $2 \%$ of dry-land and $20 \%$ of irrigated agriculture (FAO Land and Plant Nutrition Management service, http://www.fao.org/nr/aboutnr/nrl/en/). Soil salinity arises from natural or human-induced processes that inhibits plant growth via osmotically induced water deficit and/or ion toxicity if excessive sodium $\left(\mathrm{Na}^{+}\right)$and chloride $\left(\mathrm{Cl}^{-}\right)$accumulate in the shoot via transpiration [1]. Osmotic stress reduces the ability of the plant to

\footnotetext{
*Correspondence: huixia@zju.edu.cn

${ }^{\dagger}$ Equal contributors

'State Key Laboratory of Plant Physiology and Biochemistry, College of Life Sciences, Zhejiang University, Hangzhou 310058, P. R. China

Full list of author information is available at the end of the article
}

extract water from the soil and growth will reduce rapidly and significantly as salt concentration around the roots increases past a threshold level. Ion toxicity occurs when salt $\left(\mathrm{Na}^{+}\right.$and $\left.\mathrm{Cl}^{-}\right)$gains entry via the transpiration stream and accumulates in the shoot to toxic concentrations resulting in injury to cells and causing further reductions in growth $[1,2]$. Salt tolerance/sensitivity is indicated by the relative degree of biomass reduction in saline soil compared to plants in a non-saline soil, over an extended period of time [3]. Clearly water flow is linked to both types of stresses induced by salinity, yet the role of water transport in plant salt tolerance is not yet clearly defined.

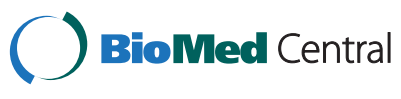

(c) 2014 Zhou et al.; licensee BioMed Central Ltd. This is an Open Access article distributed under the terms of the Creative Commons Attribution License (http://creativecommons.org/licenses/by/4.0), which permits unrestricted use, distribution, and reproduction in any medium, provided the original work is properly credited. The Creative Commons Public Domain Dedication waiver (http://creativecommons.org/publicdomain/zero/1.0/) applies to the data made available in this article, unless otherwise stated. 
Plants have evolved three distinct mechanisms of salinity tolerance including osmotic adjustment to allow turgor to be maintained, $\mathrm{Na}^{+}$and $\mathrm{Cl}^{-}$exclusion from leaf blades, and compartmentalization of $\mathrm{Na}^{+}$and $\mathrm{Cl}^{-}$at cellular or intracellular sites [1]. Numerous transporters have been identified as likely to be involved in $\mathrm{Na}^{+}$and $\mathrm{Cl}^{-}$exclusion and compartmentation [1,2,4-7], but the proteins that transport water across membranes, the aquaporins, are not considered to be directly involved in these processes, though indirect effects could occur through their impact on osmotically driven water flow and pathways for water and solute flow in roots and leaves [8].

The radial flow of water from soil solution toward the root xylem encounters a relatively high resistance compared to subsequent axial flow in the xylem to the shoot. The radial flow pathway in the root consists of the apoplastic pathway along the intracellular spaces and the cell-to-cell pathway, in which water moves through plasmodesmata or across membranes [9]. Apoplastic water flow can be blocked by Casparian bands and suberin lamellae at key cellular barriers such as the endo and exodermis $[10,11]$ where water transport across membranes occurs. Depending on the plant species and conditions, as well as the position along the root, there are variable contributions of the apoplast pathway compared to the cell-to-cell pathway [8]. The conductance of the cell-to-cell pathway can be largely determined by the activity of aquaporins (AQPs) [12]. AQPs are suggested to play a key role in plant water balance and water use efficiency [8,13-17].

Aquaporins are members of the major intrinsic protein (MIP) family, which in plants are divided into five subfamilies that include the plasma membrane intrinsic proteins (PIPs). These are considered as the main water transport pathway across plasma membranes in root and leaf tissues that play important roles in plant water relations [8,16-19]. According to the $\mathrm{N}$ terminal length of the proteins, the PIPs are further divided into two subclasses (PIP1 and PIP2). PIP1s require co-expression of PIP2s to show high water permeability in Xenopus laevis oocytes [20-27]. PIP1s and PIP2s interact affecting targeting to the plasma membrane $[20,21]$ and forming hetero-tetramers of variable stoichiometry that appears to affect their transport efficiency [27]. Plant genomes have variable numbers of aquaporin genes, ranging from 35 in Arabidopsis thaliana [28], 33 in Oryza sativa [29] and 66 in soybean, including 22 PIPs [30]. Compared with other species, little is known about the function of $A Q P$ genes in soybean.

Aquaporins are clearly involved in water transport in roots and leaves [8] and have been linked to water uptake required for cell expansion [18,26,31-35]. Water is the carrier of $\mathrm{Na}^{+}$and $\mathrm{Cl}^{-}$in the transpiration stream contributing to shoot ion toxicity, and in salinity-induced osmotic stress, free energy gradients need to be developed to drive water diffusion to the sites of cell expansion. In this context aquaporins could affect the root's ion selectivity by determining the proportion of water that flows via membrane pathways relative to the apoplast, while in osmotic stress, they could allow continued water supply under diminished osmotic and pressure gradients by increasing membrane hydraulic conductivity.

Abiotic stresses such as salt, drought and cold influence the water balance of plants and the expression of $A Q P$ genes [36]. Overexpression of several $A Q P$ genes in plants confers abiotic stress resistance. Overexpressing NtAQP1 in tobacco increased photosynthetic rate, water use efficiency and yield under salt stress [17]. Overexpression of several wheat $A Q P s$, including TaNIP, TaAQP8 and TaAQP7 genes in Arabidopsis or tobacco also increased salt tolerance or drought tolerance of the transgenic plants [37-39]. Recently, overexpression a MusaPIP1;2 in banana displayed high tolerance to multiple abiotic stresses including salt, cold and drought [40].

Soybean is a major source of protein and oil for humans and animals, yet relatively mild salt stress significantly reduces soybean growth, nodulation, seed quality and yield [41]. Recently it was found that the expression of GMPIP1;6 in roots correlated with rapid and longer term changes in root $L_{\mathrm{O}}$ in response to shoot treatments and appeared to be more concentrated in stellar tissue [42]. These results indicated that GmPIP1;6 may be important in the control of root water transport particularly in response to shoot signals. In this study, GMPIP1;6 was cloned and functionally characterized. Overexpression of GmPIP1;6 significantly increased salt tolerance of soybean by improving root $L_{\mathrm{o}}$ and $\mathrm{Na}^{+}$ exclusion.

\section{Results}

\section{Subcellular localization of GmPIP1;6}

In soybean, GmPIP1;6 was proposed to be one of the major water transporter genes in roots [42]. The full-length cDNA of GmPIP1;6 (Phytozome No. Gm08g01860.1) was amplified from soybean roots cultivar Williams 82 by PCR. The cDNA of GmPIP1;6 is comprised of 1128 bp with an 870 bp open reading frame. The GmPIP1; 6 belongs to the PIP1 subgroup and has an orthologous gene, GmPIP1;5, in the soybean genome (Additional file 1: Figure S1). GmPIP1;6 protein contains the characteristic motifs of PIPs and is predicted to be localized on the plasma membrane. To verify the subcellular localization of GmPIP1;6, the GmPIP1;6 was fused with green fluorescent protein (GFP) and driven by a constitutive Cauliflower mosaic virus $35 \mathrm{~S}$ promoter (CaMV 35S). The final construct GmPIP1;6::GFP was transiently co-expressed in onion epidermal cells and compared with the mCherry plasma membrane marker (Figure 1). GFP fluorescence of GmPIP1;6 was confined to the plasma membrane and co-localized with the RFP fluorescence of 

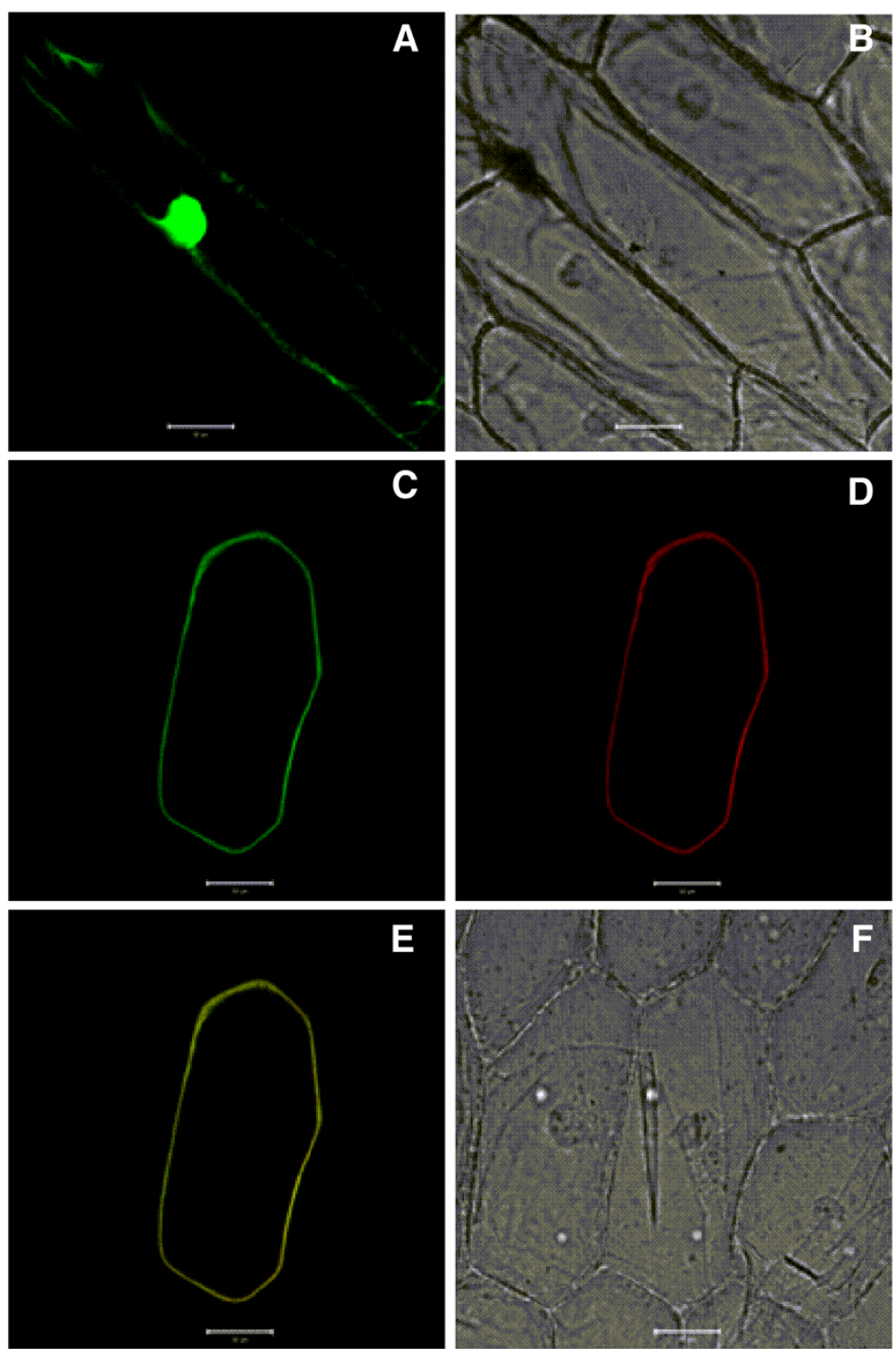

Figure 1 Subcellular localization of GmPIP1;6. (A) Green fluorescence image of an epidermal cell expressing the pCAMBIA1302 that sGFP was under the control of the CaMV 355 promoter. (B) Bright-field light image of an epidermal cell expressing the pCAMBIA1302. (C) Green fluorescence image of an epidermal cell expressing the GmPIP1;6:sGFP fusion protein. (D) Red fluorescence image of an epidermal cell expressing the CD3-1007 marker. (E) Merged fluorescence image of an epidermal cell expressing the GmPIP1;6:5GFP fusion protein and CD3-1007 marker. (F) Bright-field light image of an epidermal cell expressing the GmPIP1;6:sGFP fusion protein and CD3-1007 marker. Bars $=50 \mu \mathrm{m}$.

mCherry. When the control construct with GFP alone was transiently expressed in onion epidermal cells, the GFP fluorescence was observed in the nucleus and cytoplasm (Figure 1).

\section{Expression patterns of GmPIP1;6}

To analyze GmPIP1;6 gene expression in different soybean tissues, we measured the expression of GMPIP1;6 in root, stem, unifoliolate leaf, trifoliolate leaf, flower and pod by quantitative RT-PCR. This showed that GmPIP1;6 was highly expressed in root, stem, flower and pod whereas it was lowly expressed in leaves (Figure 2A). To investigate the response of GmPIP1;6 to salt stress, we determined expression of GmPIP1;6 in root and leaf after $100 \mathrm{mM} \mathrm{NaCl}$ treatment for 6 hours, 12 hours, 1 day, 3 days and 5 days. The expression of GmPIP1; 6 was suppressed by $\mathrm{NaCl}$ treatment in 6 and 12 hours in both roots and leaves. However, expression was induced in the roots after 1 day and further increased at 3 days and 5 days of $\mathrm{NaCl}$ treatment (Figure 2B). A similar response was observed in the leaves although the absolute expression of GmPIP1;6 was much lower than that of the roots (Additional file 1: Figure S2). 


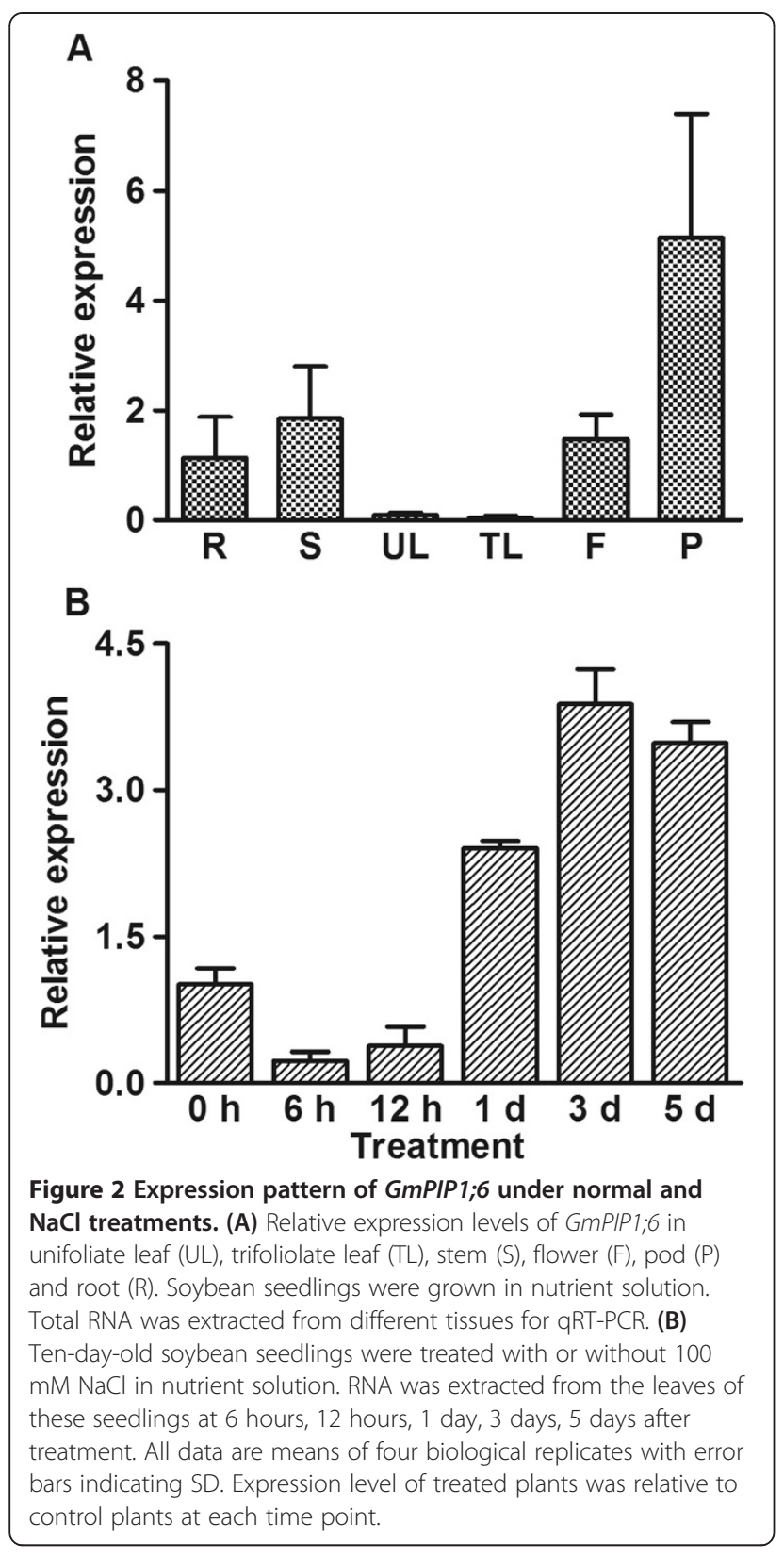

\section{Generation of transgenic soybean overexpressing GmPIP1;6}

To characterize the role of GMPIP1;6 in salt stress, the cDNA of GMPIP1;6 driven by a modified CaMV 35S promoter was introduced into soybean via soybean cotyledonary node transformation system (Figure 3A). Positive transgenic lines were selected by spraying the herbicide Liberty (Additional file 1: Figure S3). A total of 11 independent lines which overexpressed GmPIP1;6 were generated and confirmed by semi-qRT PCR (Figure 3B). Two transgenic lines were selected and measured by qRTPCR. These two lines, which showed more than 100-fold higher expression levels of GmPIP1;6 than WT control in leaves (Figure $3 \mathrm{C}$ ), were selected for further experiments.

\section{Overexpression of GmPIP1;6 enhances salt tolerance in soybean}

The growth of WT and GmPIP1;6-Oe transgenic soybean plants were similar when grown in aerated hydroponic solution (Figure 4A, Table 1). For salt tolerance analysis, 10-day-old WT and GmPIP1;6-Oe transgenic seedlings were treated with $100 \mathrm{mM} \mathrm{NaCl}$ for 7 days. Salt treatment suppressed the growth of WT and GMPIP1;6-Oe transgenic soybean plants, all of which exhibited a decreased plant length and fresh weight in both leaves and roots (Figure 4A, Table 1). However, the leaves of WT plants turned yellow after treatment for 7 days while the leaves of transgenic plants were still green (Figure 4A). The relative measure of leaf greenness was carried out with a portable chlorophyll meter. Soil-plant analyser development (SPAD) values of unifoliolate leaf in GMPIP1;6-Oe were significantly higher than WT under salt stressed condition (Figure 4B). Moreover, the shoot length and fresh weight of GmPIP1;6-Oe transgenic soybean were significantly higher than that of WT plants under salt stressed conditions (Table 1). These results indicated that GmPIP1;6-Oe plants were more tolerant to salt stress than WT plants.

\section{Overexpression of GmPIP1;6 increased photosynthesis and root water conductance in soybean under salt stress conditions}

The impact of GmPIP1;6 overexpression on net assimilation $\left(\mathrm{A}_{\mathrm{N}}\right)$ under saturating light, stomata conductance $\left(g_{s}\right)$ and transpiration rate $\left(T_{r}\right)$ were measured using an infrared gas analyser (LI-6400) under normal and salt treatment conditions. Diurnal photosynthesis of soybean was measured every 2 hours in a light period from 8:00 AM to 4:00 PM. As expected, the $A_{N}, g_{s}$ and $T_{r}$ showed diurnal changes and peaked at about 2:00 PM in both WT and GmPIP1;6-Oe plants (Figure 5A-C). Under normal growth conditions, GmPIP1;6-Oe plants showed significantly higher $A_{N}, g_{s}$ and $T_{r}$ than that of WT at all the time points measured (Figure 6A-C). We then took the values of $\mathrm{A}_{\mathrm{N}}, \mathrm{g}_{\mathrm{s}}$ and $\mathrm{T}_{\mathrm{r}}$ at 2:00 PM to compare WT and GmPIP1;6-Oe plants. Under normal growth conditions, $\mathrm{A}_{\mathrm{N}}, \mathrm{g}_{\mathrm{s}}$ and $\mathrm{T}_{\mathrm{r}}$ was significantly increased in GMPIP1;6Oe plants than that of WT plants (Table 2). Interestingly, the $A_{N}, g_{s}$ and $T_{r}$ was more than 2-fold higher in GmPIP1;6-Oe1 plants compared with that of WT under salt treatment. In the other transgenic line, GmPIP1;6Oe2, the $A_{N}, g_{s}$ and $T_{r}$ were 1.71, 1.75 and 2.1-fold higher than that of WT (Table 2). These results indicated that overexpression of GmPIP1;6 increased photosynthetic activity and stomatal conductance, especially under saline conditions. 

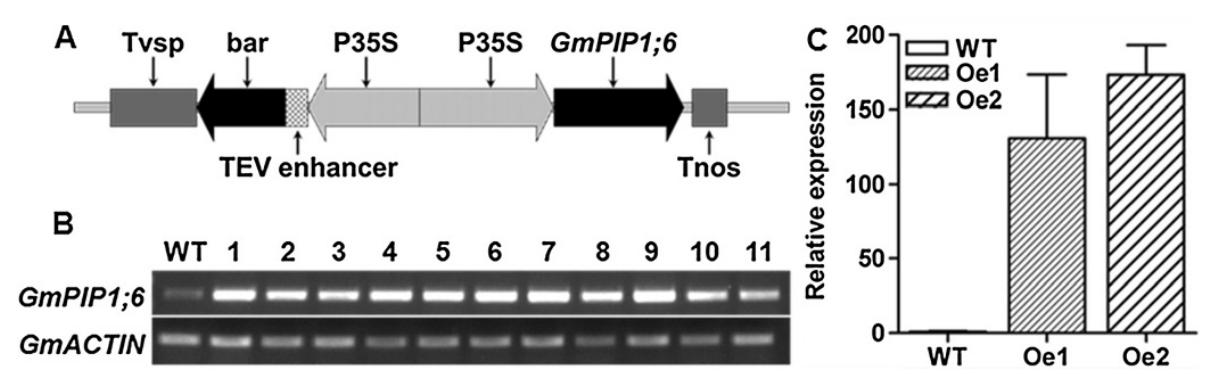

Figure 3 Construction of GmPIP1;6 overexpression transgenic soybean. (A) Schematic illustration of T-DNA sequence of GmPIP1;6 overexpression vector. (B) Reverse transcript PCR analysis of GmPIP1;6 overexpression transgenic lines. 1 to 11 represented 11 independent $\mathrm{T}_{1}$ generation GmPIP1;6 overexpression lines. WT, wild type. (C) qRT-PCR analysis of two representative GmPIP1;6 overexpression transgenic lines. RNA was extracted from the leaves of fourteen-day-old seedlings. All data are means of four biological replicates with error bars indicating SD. Expression of GmACTIN was used as the internal control.

Under normal conditions, the substomatal concentration of $\mathrm{CO}_{2}\left(\mathrm{C}_{\mathrm{i}}\right)$ of GmPIP1;6-Oe was lower than that of WT though no significant difference was observed. In contrast, the $\mathrm{C}_{\mathrm{i}}$ of GmPIP1;6-Oe was significantly lower than that of WT under salt treatment (Table 2, Figure 6D). This is in accordance with the higher rate of net photosynthesis of GmPIP1;6-Oe compared to WT plants under saline conditions. Instantaneous water use efficiency $(\mathrm{IWUE}=\mathrm{A} / \mathrm{T})$ was significantly increased in GmPIP1;6-Oe plants under both normal and salt stress conditions compared with WT (Table 2). Changing stomata density and/or pore area will influence the $g_{s}$ and $\mathrm{T}_{\mathrm{r}}$. Examination of the abaxial leaf surface revealed a significantly wider stomatal aperture in GmPIP1;6-Oe plants under both normal and salt stress conditions while the stomata density was not changed (Table 2, Additional file 1: Figure S4A). As a result, the water loss rate was increased in the transgenic plants compared with WT plants (Additional file 1: Figure S4B).

We also measured root hydraulic conductance $\left(L_{\mathrm{o}}\right)$, normalized to root dry weight, in GmPIP1;6-Oe and WT plants. Interestingly the $L_{\mathrm{o}}$ was similar between GmPIP1;6Oe and WT plants irrigated with nutrient solution. However when irrigated with nutrient solution containing 50 $\mathrm{mM} \mathrm{NaCl}, L_{\mathrm{o}}$ of WT plants decreased almost $50 \%$ while $L_{\mathrm{o}}$ of GmPIP1;6-Oe plants remained unchanged (Figure 5).

\section{Overexpression of GmPIP1;6 affects Na uptake and exclusion of transgenic plants under salt stress}

The sodium concentration of plants was analyzed under normal and salt stress conditions. Sodium $\left(\mathrm{Na}^{+}\right)$concentration was similar between WT and GmPIP1;6-Oe plants in roots and leaves under normal conditions (Figure 7A, B). Salt treatment increased $\mathrm{Na}^{+}$concentration in the roots and leaves of both WT and GmPIP1; 6-Oe plants. However, the $\mathrm{Na}^{+}$concentration was significantly lower in the leaves of GMPIP1;6-Oe plants than WT plants under salt stress (Figure 7B, Additional file 1: Figure S5). We examined relative $\mathrm{Na}^{+}$exclusion of
WT and GmPIP1;6-Oe plants after salt treatment revealing that the relative exclusion of $\mathrm{Na}^{+}$from the shoot of GmPIP1;6-Oe plants was higher relative to WT (Figure 7C). Moreover, salt treatment induced the expression of GmNHX1 in the leaves and roots of WT but not in GmPIP1;6-Oe plants (Figure 8).

\section{Overexpression of GmPIP1;6 increased yields of soybean in the field}

Four independent GmPIP1;6-Oe lines, where two of these lines were the same as the ones used in the physiology experiments, were grown in field conditions for an entire growing season in two continuous years. Each year, the transgenic plants were compared with WT and null transgenic plants, which were segregated from heterozygous transgenic plants. Interestingly, GmPIP1;6-Oe plants have a significantly higher seed weight per plant and per 100 seeds than WT (Table 3). Other yield parameters were similar between WT and GmPIP1;6-Oe plants (Table 3, Additional file 1: Figure S6A). A detailed analysis showed that the increased seed weight of GmPIP1;6-Oe plants was caused by large seed size (Additional file 1: Figure S6B, Table 3).

\section{Discussion}

Recently, $66 A Q P$ genes were identified in soybean by a genome wide analysis [30]. The GmPIP subfamily contained 8 PIP1 genes and 14 PIP2 genes, all of which were predicted to localize on the plasma membrane. It is found that PIP2 aquaporins when expressed in Xenopus oocytes have high water permeability while PIP1 aquaporins do not. However, PIP1 aquaporins can work cooperatively with PIP2s in targeting to the plasma membrane and in water permeation as heterotetramers [20-27]. This is accordance with the fact that GmPIP1;6 protein fused with GFP localized on the plasma membrane (Figure 1).

GmPIP1;6 is the ortholog of AtPIP1;2, NtAQP1, HvPIP1;6/1;1 and TaAQP8 in Arabidopsis, tobacco, barley 


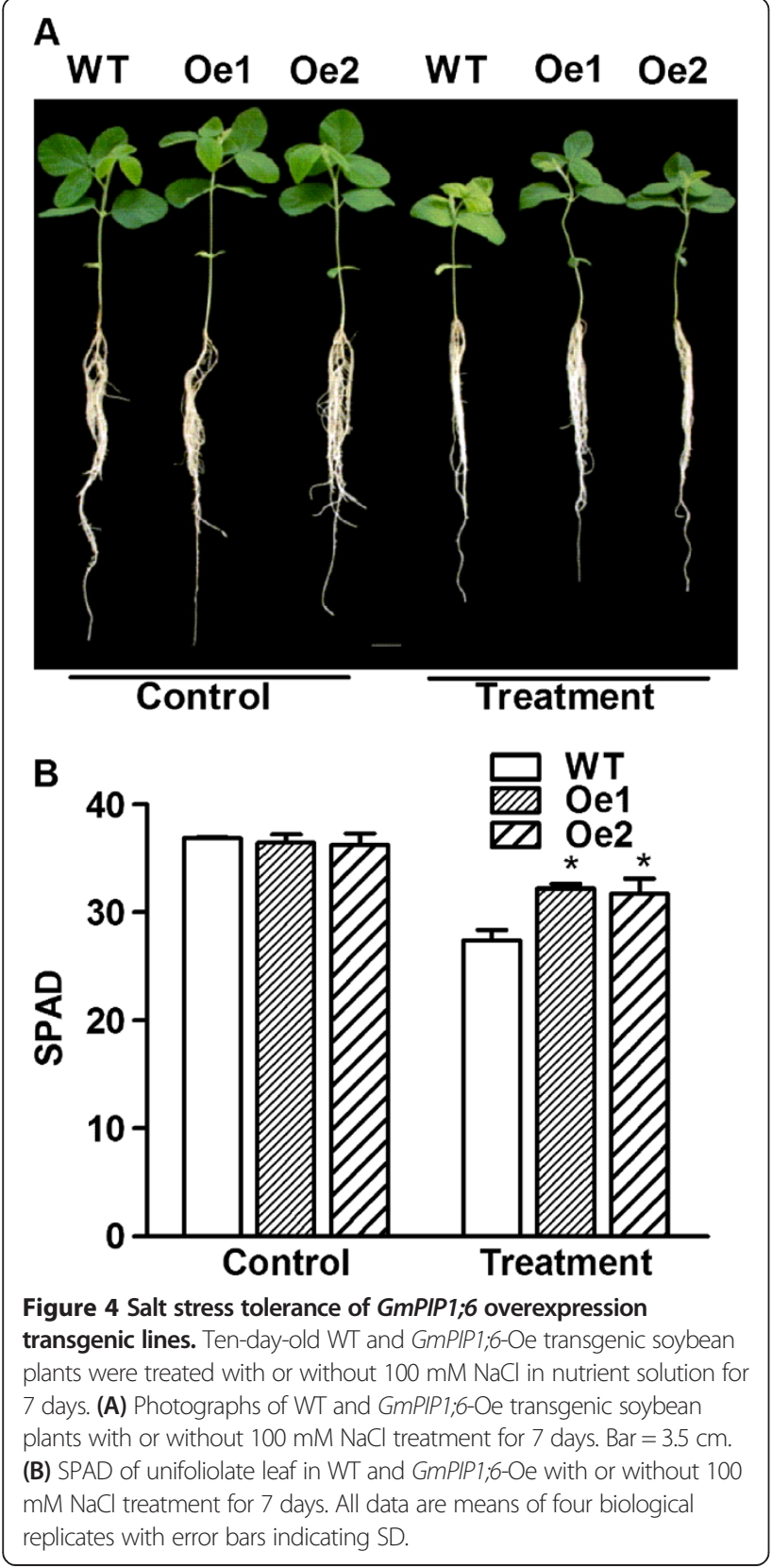

and wheat (Additional file 1: Figure S1). AtPIP1;2 and NtAQP1 play a key role in regulating root hydraulic conductance $\left(L_{\mathrm{o}}\right)$ in Arabidopsis and tobacco [17,43,44], respectively. In situ PCR showed that GmPIP1;6 was highly expressed in the stellar region of the root [42], which is similar as NtAQP1. Shoot topping rapidly decreased root hydraulic conductance $\left(L_{\mathrm{o}}\right)$ by $50 \%$ to $60 \%$, which is correlated with the reduced expression of GmPIP1;6 in roots of soybean. Therefore, GmPIP1; 6 was suggested to control the $L_{\mathrm{o}}$ as AtPIP1;2 and NtAQP1.

Water stress caused by drought, salt or cold has a complex effect on the expression of $A Q P$ genes [36]. In summary, the expression of $A Q P$ genes could be divided
Table 1 Plant length and biomass of the WT and transgenic plants under normal and salt stress conditions

\begin{tabular}{llllll}
\hline Genotype & \multicolumn{2}{l}{ Plant length $(\mathbf{c m})$} & & \multicolumn{2}{l}{ Plant fresh weight $(\mathbf{g})$} \\
\cline { 2 - 3 } & Shoot & Root & & Shoot & Root \\
\hline Normal condition & & & & \\
WT & $22.2 \pm 1.5^{\mathrm{ab}}$ & $38.0 \pm 2.1^{\mathrm{a}}$ & & $3.10 \pm 0.13^{\mathrm{a}}$ & $1.15 \pm 0.09^{\mathrm{a}}$ \\
Oe1 & $22.8 \pm 0.8^{\mathrm{a}}$ & $38.2 \pm 2.5^{\mathrm{a}}$ & $3.08 \pm 0.08^{\mathrm{a}}$ & $1.16 \pm 0.11^{\mathrm{a}}$ \\
Oe2 & $22.7 \pm 0.5^{\mathrm{a}}$ & $37.7 \pm 2.2^{\mathrm{a}}$ & $3.10 \pm 0.15^{\mathrm{a}}$ & $1.15 \pm 0.06^{\mathrm{a}}$ \\
Salt stress condition & & & & \\
WT & $15.7 \pm 1.0^{\mathrm{d}}$ & $33.0 \pm 4.0^{\mathrm{ab}}$ & $1.72 \pm 0.18^{\mathrm{c}}$ & $0.67 \pm 0.10^{\mathrm{b}}$ \\
Oe1 & $19.0 \pm 1.3^{\mathrm{bc}}$ & $28.8 \pm 3.7^{\mathrm{b}}$ & $2.39 \pm 0.17^{\mathrm{b}}$ & $0.76 \pm 0.10^{\mathrm{b}}$ \\
Oe2 & $18.5 \pm 1.6^{\mathrm{c}}$ & $29.0 \pm 3.1^{\mathrm{b}}$ & $2.28 \pm 0.07^{\mathrm{b}}$ & $0.71 \pm 0.07^{\mathrm{b}}$ \\
\hline
\end{tabular}

Ten-day-old WT and GmPIP1;6-Oe transgenic soybean plants were treated with or without $100 \mathrm{mM} \mathrm{NaCl}$ for 7 days. Length and fresh weight of shoot and root of WT and transgenic plants were measured. Data are given as means \pm $S D(n=6)$. Different letters indicate significant differences (LSD test, $P<0.05)$.

into two stages. In the early stress response, the plant usually suppresses the expression of PIP genes, which is hypothesised to avoid water flow from the root to the soil when the soil water potential decreases [45,46]. After a few days of acclimation, the expression of PIP genes recovers or even increases and is correlated with increased hydraulic conductance [47-49]. The expression of GmPIP1;6 in both roots and leaves showed this two stage response under salt stress (Figure 2B, Additional file 1: Figure S2), indicating GmPIP1;6 may be involved in the salt stress acclimation of soybean.

Overexpression of several PIP1 genes increased the hydraulic conductance and salt tolerance of the transgenic plants, such as NtAQP1, OsPIP1;1, TaAQP8 and MusaPIP1;2 [17,37,40,50]. Here we show that GmPIP1;6 conferred salt tolerance, but also under normal conditions the overexpression resulted in higher growth and greater yield under field conditions compared to WT plants (Figure 4A, Table 3). However, the mechanism of how these PIP1 genes can improve plant growth and salt tolerance is largely unknown, though a high $\mathrm{K}^{+} / \mathrm{Na}^{+}$ratio was mentioned with overexpression of TaAQP8 [37].

It is highly unlikely that GmPIP1;6 can transport $\mathrm{Na}^{+}$, therefore salt tolerance of transgenic GmPIP1;6 plants is more likely to occur through indirect mechanisms: First, improvement in water uptake by roots and leaf cell hydration, could improve energy capture and conversion by leaves. Greater energy availability in turn could improve $\mathrm{Na}^{+}$exclusion by roots and improve tissue $\mathrm{Na}^{+}$ compartmentalization [1]. We compared the root $L_{\mathrm{o}}$ of WT and GmPIP1;6-Oe plants under normal and salt stressed conditions (Figure 7). As expected, $\mathrm{NaCl}$ treatment decreased $L_{\mathrm{o}}$ by $50 \%$ in WT plants. In contrast, GmPIP1;6-Oe plants maintained $L_{\mathrm{o}}$ under salt stress conditions. Therefore, GmPIP1;6-Oe plants may have a higher water uptake activity than WT plants under 


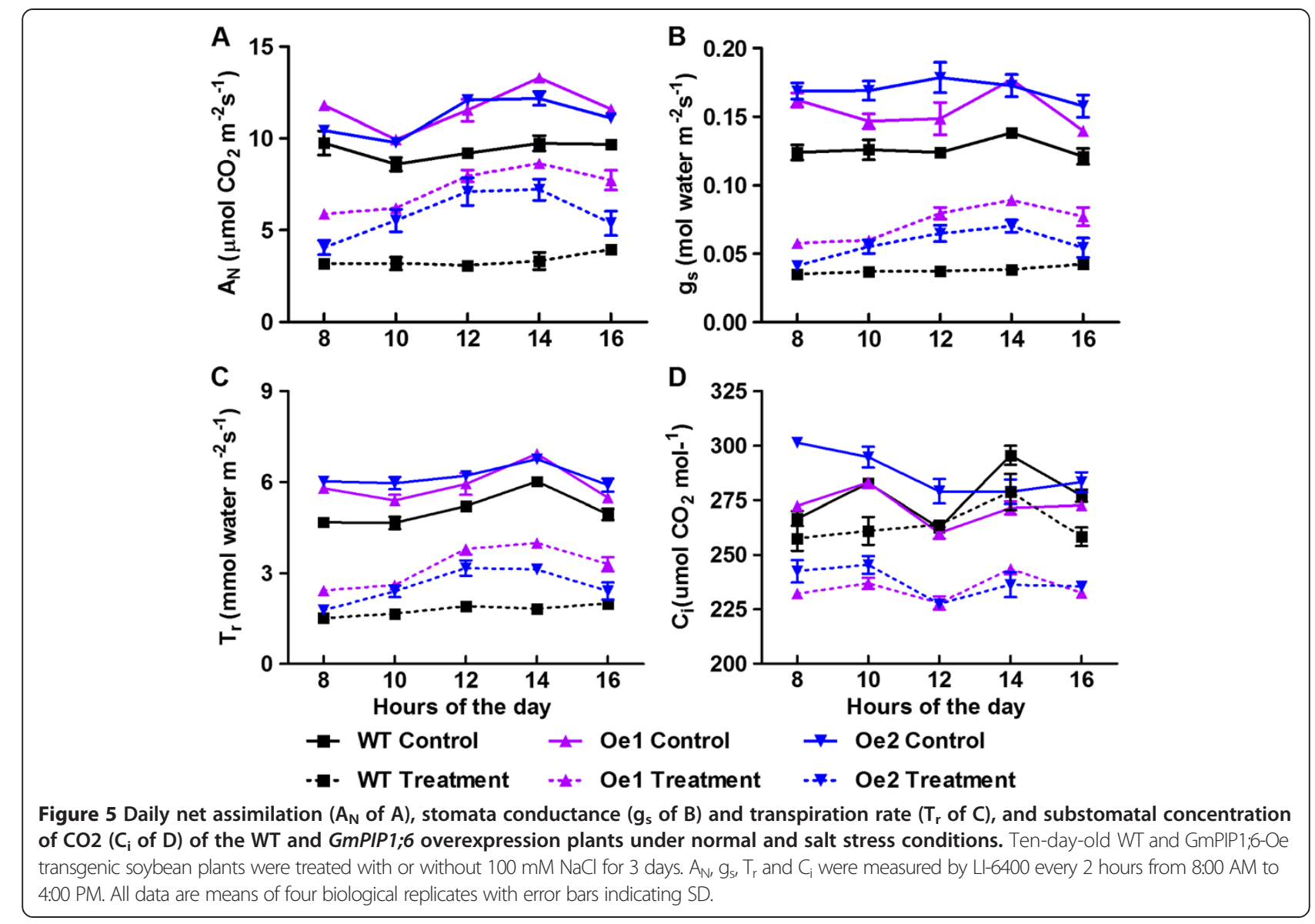

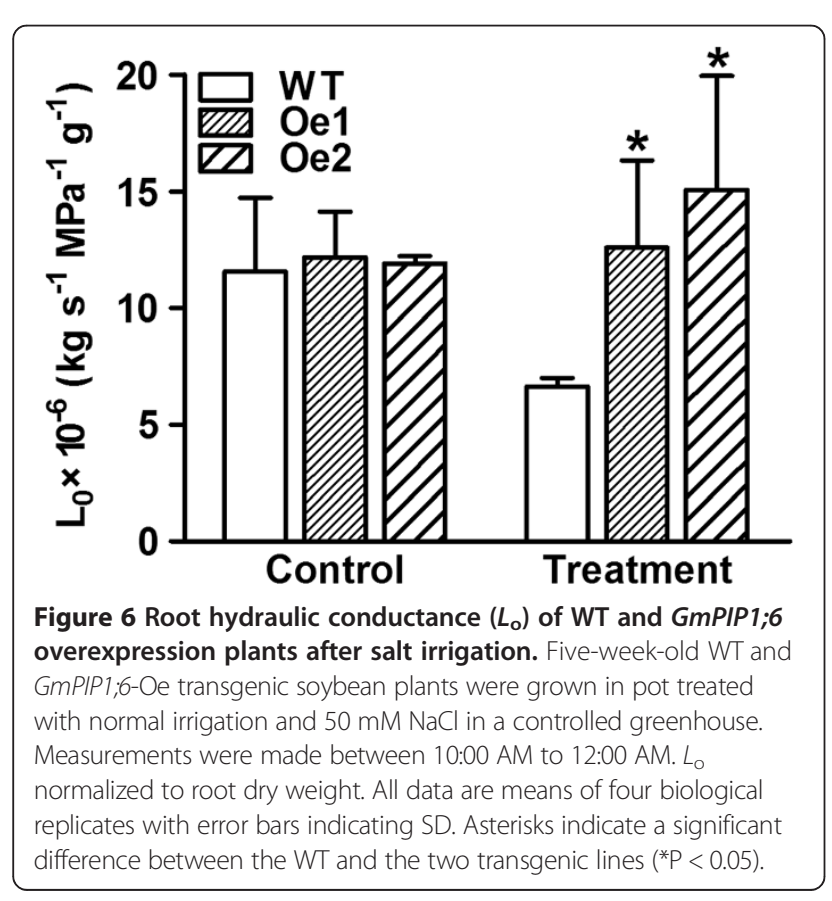

saline conditions. Secondly, $\mathrm{Na}^{+}$is transported to shoots in the transpiration stream through the xylem, but it can return to root via the phloem [43,51-53]. Export of $\mathrm{Na}^{+}$ from leaves in the phloem could conceivably help to maintain low salt concentration in the leaves and may be enhanced by greater water permeability in phloem cells. Also we show that net assimilation and gas exchange are enhanced in the GmPIP1;6-Oe plants, and especially so under saline conditions compared to WT. This would potentially translate to a higher capacity to exclude $\mathrm{Na}^{+}$via energy demanding salt exclusion mechanisms in the roots and the leaves. Thirdly, we measured the expression of GmNHX1 [54] to analyze the effect of $\mathrm{Na}^{+}$compartmentalization in the vacuole (Figure 8). Salt treatment induced the expression of GmNHX1 in the leaves and roots of WT but not in GmPIP1;6-Oe plants. This is accordance with the lower $\mathrm{Na}^{+}$concentration of GmPIP1;6-Oe plants and indicated that vacuole compartmentalization of GmPIP1;6-Oe plants was not necessarily enhanced.

Another possibility that may account for reduced $\mathrm{Na}^{+}$ transport to the shoot in the over expressing plants could be that more water flow occurs radially across roots via the cell-to-cell (membrane) pathway, as opposed to the apoplast 
Table 2 Photosynthetic and root hydraulic characteristics of WT and transgenic plants under normal and salt stress conditions

\begin{tabular}{|c|c|c|c|c|c|c|}
\hline \multirow[t]{2}{*}{ Variable } & \multicolumn{3}{|c|}{ Normal condition } & \multicolumn{3}{|c|}{ Salt stress condition } \\
\hline & WT & Oe1 & Oe2 & WT & Oe1 & Oe2 \\
\hline$g_{s}\left(m o l\right.$ water $\left.m^{-2} s^{-1}\right)$ & $0.14 \pm 0.01^{b}$ & $0.18 \pm 0.01^{a}$ & $0.17 \pm 0.02^{a}$ & $0.04 \pm 0.01^{d}$ & $0.09 \pm 0.01^{c}$ & $0.07 \pm 0.01^{c}$ \\
\hline $\mathrm{T}_{\mathrm{r}}\left(\mathrm{mmol}\right.$ water $\left.\mathrm{m}^{-2} \mathrm{~s}^{-1}\right)$ & $6.02 \pm 0.18^{b}$ & $6.93 \pm 0.52^{\mathrm{a}}$ & $6.76 \pm 0.34^{\mathrm{a}}$ & $1.83 \pm 0.46^{\mathrm{e}}$ & $3.99 \pm 0.42^{c}$ & $3.12 \pm 0.53^{d}$ \\
\hline$A_{N}\left(\mu \mathrm{mol} C \mathrm{CO}_{2} \mathrm{~m}^{-2} \mathrm{~s}^{-1}\right)$ & $9.73 \pm 1.26^{b}$ & $13.29 \pm 0.24^{\mathrm{a}}$ & $12.17 \pm 1.12^{\mathrm{a}}$ & $3.31 \pm 1.41^{d}$ & $8.26 \pm 0.56^{b c}$ & $7.21 \pm 1.74^{c}$ \\
\hline $\mathrm{C}_{\mathrm{i}}\left(\mu \mathrm{mol} \mathrm{CO}_{2} \mathrm{~mol}^{-1}\right)$ & $295 \pm 13^{\mathrm{a}}$ & $271 \pm 9^{b}$ & $278 \pm 17^{b}$ & $279 \pm 25^{d}$ & $243 \pm 7^{c}$ & $236 \pm 17^{c}$ \\
\hline Stomata pore aperture $(\mu \mathrm{m})$ & $3.48 \pm 0.27^{b}$ & $3.88 \pm 0.42^{\mathrm{a}}$ & $3.86 \pm 0.39^{a}$ & $1.93 \pm 0.14^{d}$ & $3.00 \pm 0.25^{c}$ & $2.96 \pm 0.19^{c}$ \\
\hline Stomata density $\left(0.1 \mathrm{~mm}^{2}\right)$ & $19 \pm 3^{\mathrm{a}}$ & $19 \pm 3^{\mathrm{a}}$ & $19 \pm 4^{\mathrm{a}}$ & $19 \pm 3^{\mathrm{a}}$ & $20 \pm 4^{a}$ & $19 \pm 3^{\mathrm{a}}$ \\
\hline IWUE (mmol $\mathrm{CO}_{2} \mathrm{mmol}^{-1}$ water) & $1.61 \pm 0.16^{c}$ & $1.92 \pm 0.15^{b}$ & $1.88 \pm 0.24^{b}$ & $1.73 \pm 0.35^{b c}$ & $2.17 \pm 0.09^{a}$ & $2.29 \pm 0.22^{a}$ \\
\hline
\end{tabular}

Ten-day-old WT and GmPIP1;6-Oe transgenic soybean plants were treated with or without $100 \mathrm{mM} \mathrm{NaCl}$ for 3 days. Data are given as means \pm SD ( $\mathrm{n}=4$ ). Different letters indicate significant differences (LSD test, $\mathrm{P}<0.05$ ).

pathway. This would occur because of the higher activity of GmPIP1;6 in root membranes under salinity stress demonstrated by the higher root $L_{\mathrm{o}}$ compared to WT. A higher proportion of water flow via the membrane pathway in roots would confer a greater degree of ion selectivity relative to flow in the apoplast pathway. Altogether, we clarified that overexpression of GmPIP1;6 increased soybean salt tolerance by maintaining water uptake ability and $\mathrm{Na}^{+}$exclusion.

In addition to function as a water channel, AtPIP1;2 and NtAQP1 may function to facilitate $\mathrm{CO}_{2}$ transport and enhance photosynthesis by increasing the mesophyll conductance to $\mathrm{CO}_{2}$ diffusion [55-59]. Overexpression of NtAQP1 in tobacco and tomato increased the $\mathrm{A}_{\mathrm{N}}$, which resulted in increased WUE. The overexpression of NtAQP1 produced higher dry biomass and yield under normal irrigation and salt stressed conditions [17]. GmPIP1;6-Oe plants also exhibited higher $\mathrm{A}_{\mathrm{N}}, \mathrm{g}_{\mathrm{s}}$ and IWUE than WT under both normal and saline conditions (Figure 6, Table 2). However, the growth of GmPIP1;6-Oe plants was only enhanced under saline conditions compared to WT plants (Figure 4A, Table 1). Whether GmPIP1;6 has a similar function as NtAQP1 to facilitate $\mathrm{CO}_{2}$ diffusion across leaf cell membranes requires further research.

Importantly, GmPIP1;6-Oe plants showed higher yield in the field than WT because the seed weight and size of GmPIP1;6-Oe were increased (Table 3, Additional file 1: Figure S6). This may be reflecting the higher net assimilation, but also may indicate sink limitation of seed loading that could be enhanced by greater water permeability in the seed loading process [60]. In addition to being highly expressed in roots and stems, the transcripts of GmPIP1;6Oe were abundant in flower and pod, which supports a role of GmPIP1;6-Oe in seed loading of assimilates via enhanced water permeability.

\section{Conclusions}

In this study, the function of GmPIP1;6 was analyzed by constitutive expressing in the soybean plants. The expression of GmPIP1;6 was influenced by salt stress. Overexpression of GmPIP1;6 improved salt tolerance of transgenic plants by increasing water transport, photosynthesis and $\mathrm{Na}^{+}$exclusion. Moreover, the yield of GmPIP1;6 overexpression plants was improved in the field indicating the potential of GmPIP1;6 in genetic engineering of soybean.

\section{Methods}

Plant materials, growth conditions and treatments

Soybean cultivar Williams 82 was used for all physiological experiments and soybean transformation. Seeds were germinated in nursery pots with sand. Five days after germination, the seedlings grown uniformly were transferred into pots with nutrient solution or soil. 1/2 Hoagland solution was used for hydroponic culture containing $2.5 \mathrm{mM} \mathrm{KNO} 3,2.5 \mathrm{mM} \mathrm{Ca}\left(\mathrm{NO}_{3}\right)_{2}, 0.5 \mathrm{mM}$ $\mathrm{KH}_{2} \mathrm{PO}_{4}, 0.25 \mathrm{mM} \mathrm{K} \mathrm{SO}_{4}, 1 \mathrm{mM} \mathrm{MgSO}{ }_{4}, 0.1 \mathrm{mM} \mathrm{Fe}-$ $\operatorname{EDTA}(\mathrm{Na}), 4.57 \mu \mathrm{M} \mathrm{MnCl}_{2}, 3.8 \mu \mathrm{M} \mathrm{ZnSO}_{4}, 0.09 \mu \mathrm{M}$ $\left(\mathrm{NH}_{4}\right)_{6} \mathrm{Mo}_{7} \mathrm{O}_{24}, 23 \mu \mathrm{M} \mathrm{H}_{3} \mathrm{BO}_{3}, 1.57 \mu \mathrm{M} \mathrm{CuSO}_{4}$. Plants were grown in green house under $12 \mathrm{~h}$ light $/ 12 \mathrm{~h}$ dark photoperiod with light intensity of $1000 \mu \mathrm{mol} \mathrm{m}{ }^{-2} \mathrm{sec}^{-1}$ and day/night temperatures of $30 / 22^{\circ} \mathrm{C}$. Humidity of the growth room was controlled at approximately $30 \%$.

Ten-day-old seedlings were transferred into nutrient solution with or without $100 \mathrm{mM} \mathrm{NaCl}$. The nutrient solution was changed every two days. In the soil experiments, plants were irrigated nutrient solution every three days.

\section{Subcellular localization of GmPIP1;6}

Full length cDNA of GmPIP1;6 without stop code was amplified via PCR using the primers in Supplementary Additional file 2: Table S1. The PCR product was cloned into vector pCAMBIA1302 under the control of the CaMV $35 \mathrm{~S}$ promoter. The resulting construct (pCAMBIA1302:GmPIP1;6) placed GmPIP1;6 in-frame, upstream of the sGFP. Plasmids DNA of pCAMBIA1302: GmPIP1;6 and CD3-1007 (AtPIP2A::mCherry fusion) 


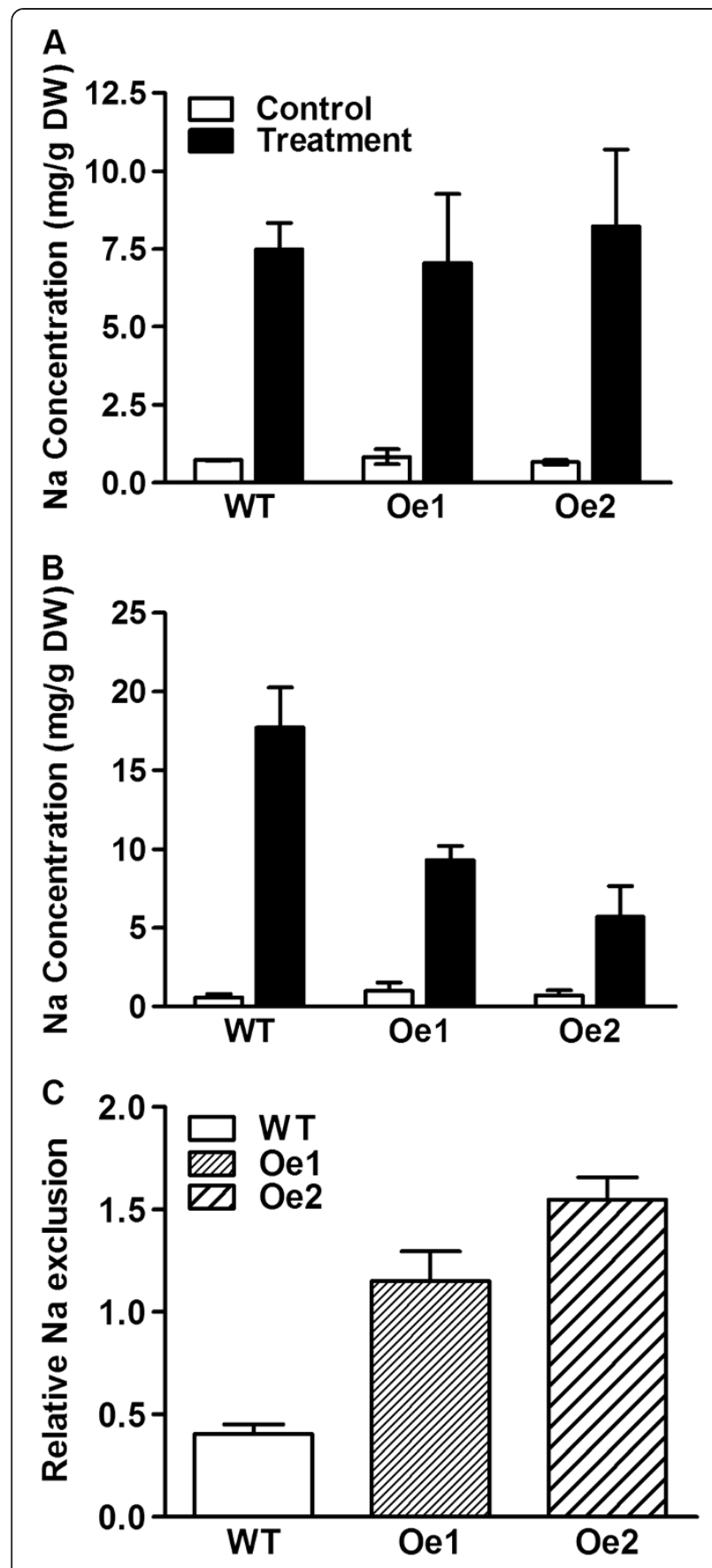

Figure 7 lon concentration in WT and GMPIP1;6 overexpression plants in hydroponics condition. (A) and (B) The content of $\mathrm{Na}^{+}$ in roots and leaves. Ten-day-old WT and GMPIP1;6-Oe transgenic soybean plants were treated with or without $100 \mathrm{mM} \mathrm{NaCl}$ for 7 days. The roots or leaves of these seedlings were sampled for measurement. (C) Relative Na exclusion. Data are means of four biological replicates with error bars indicating SD. Asterisks indicate a significant difference between the WT and the transgenic lines $(* * P<0.01)$. DW, dry weight. was mix with $50 \mu \mathrm{l}$ gold particles and bombarded into onion inner epidermal cells using the Biolistic PDS-1000/ He particle delivery system (BIO-RAD). Fluorescence was observed by confocal laser scanning microscopy (LSM700; Carl Zeiss) after incubation at $25^{\circ} \mathrm{C}$ for $16-18 \mathrm{~h}$ on MS medium in dark.

\section{Construction of transgenic plants}

Full-length cDNA of GmPIP1;6 was amplified by PCR with cDNA of Williams 82 and ligated into pMD-18 T vector (Takara). After sequencing, the correct GmPIP1;6 was digested from pMD-18 T vector using BamHI and $X b a \mathrm{I}$ restriction enzymes. GmPIP1;6 was then cloned into binary plasmid pTF101-35S which was modified by introducing CaMV $35 \mathrm{~S}$ promoter and nos terminator into pTF101. The vector was transformed into Williams 82 via Agrobacterium tumefaciens media soybean cotyledon node transformation system as described [61].

\section{RNA extraction}

Total RNA was isolated from tissues of soybean cultivar Williams 82 using TRIzol reagent (Invitrogen, Carlsbad, CA) according the manufacturer's instruction. $50 \mathrm{mg}$ soybean tissues with three bilogical replicate were quickly harvested, frozen in liquid nitrogen and stored at $-80^{\circ} \mathrm{C}$. Contaminating DNA was removed with DNaseI treatment for $20 \mathrm{~min}$ at $25^{\circ} \mathrm{C}$ (Takara), and RNA was stored at $-80^{\circ} \mathrm{C}$. Total RNA was quantified with nanodrop.

\section{Semi-quantitative RT-PCR and quantitative real-time PCR} First-strand cDNAs were synthesized from total RNA using SuperScript II reverse transcriptase (Invitrogen). Semi-quantitative RT-PCR was performed using a pair of gene-specific primers. The housekeeping gene GmACTIN was used as an internal control. Quantitative real-time PCR was performed using a SYBR Green I on a Light Cycler 480 II machine (Roche Diagnostics), according to the manufacturer's instructions. The amplification program for SYBR Green I was performed at $94^{\circ} \mathrm{C}$ for $10 \mathrm{sec}, 58^{\circ} \mathrm{C}$ for $10 \mathrm{sec}$ and $72^{\circ} \mathrm{C}$ for $10 \mathrm{sec}$. Triplicate quantitative assays were performed on each cDNA sample. The relative level of expression was calculated using the formula $2^{-\Delta(\Delta \mathrm{cp})}$. All primers used for RT-PCR are given in Supplementary Additional file 2: Table S1.

\section{Gas-exchange measurements}

Homozygous lines were selected from the $\mathrm{T}_{2}$ generation of transgenic GmPIP1;6 overexpression plants and used for the physiology experiment. $A_{N}, g_{s}, T_{r}$ and $C_{i}$ were recorded in GmPIP1;6 overexpression and control plants in green house on fully expanded leaves, using an Li-6400 portable gas-exchange system (LI-COR). All measurements were conducted between 8:00 AM and 4:00 PM. Photosynthesis 

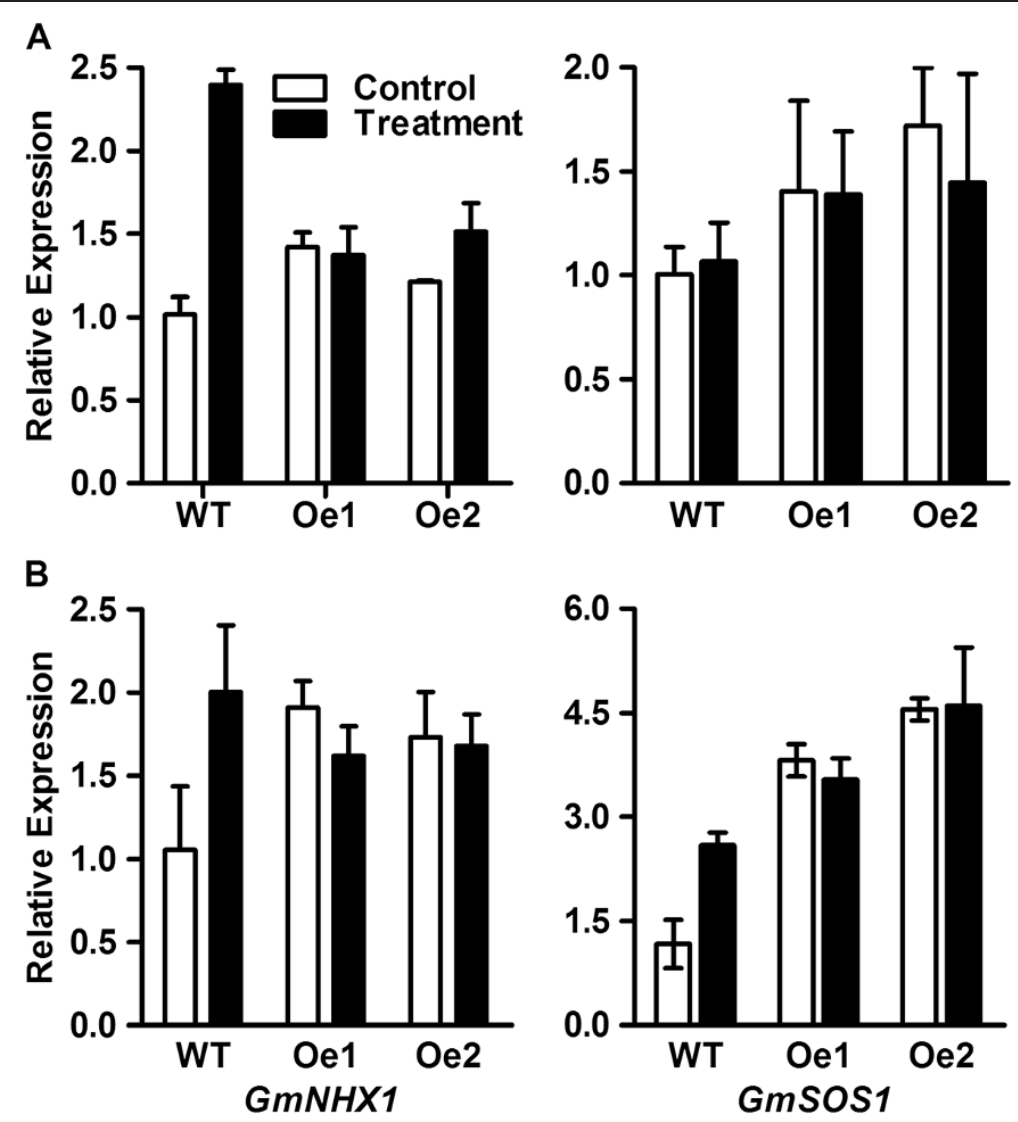

Figure 8 Expression analysis of soybean salt response gene. (A) and (B) The expression of GmNHX1 and GmSOS1 in leaves and root under normal or salt stress conditions. RNA was extracted from leaves and roots of 10-day-old WT and GMPIP1;6 overexpression plants treated with or without $100 \mathrm{mM} \mathrm{NaCl}$ for 3 days. All data are means of four biological replicates with error bars indicating SD. Expression of GmACTIN was used as the internal control.

was induced in saturating light $\left(1000 \mu \mathrm{mol} \mathrm{m} \mathrm{m}^{-2} \mathrm{~s}^{-1}\right)$ with

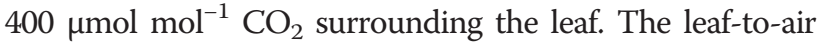
VPD was kept at around 2 to $4 \mathrm{kPa}$ and leaf temperature was approximately $30^{\circ} \mathrm{C}$ (ambient temperature) during all measurements. For each treatment, there were four biological replicates.

\section{Stomata aperture and density}

Epidermis of soybean abaxial leaf was separation by forceps. All samples were collected around 2:00 PM (at peak transpiration). Counting and photographing were performed with a bright-field microscope (80i; Nikon) mounted with a camera. Stomata images were later

Table 3 Agronomic characteristics of WT, null transgenic and overexpression transgenic soybean plants in field

\begin{tabular}{ccccccc}
\hline Genotype & WT & Negative & Oe1 & Oe2 & Oe3 & Oe4 \\
\hline Plant height $(\mathrm{cm})$ & $83 \pm 3^{\mathrm{a}}$ & $87 \pm 8^{\mathrm{a}}$ & $83 \pm 8^{\mathrm{a}}$ & $89 \pm 10^{\mathrm{a}}$ & $83 \pm 15^{\mathrm{a}}$ & $87 \pm 6^{\mathrm{a}}$ \\
Branch number & $4.6 \pm 1.1^{\mathrm{a}}$ & $5.6 \pm 2.1^{\mathrm{a}}$ & $4.7 \pm 1.4^{\mathrm{a}}$ & $4.8 \pm 2.1^{\mathrm{a}}$ & $5.4 \pm 2.3^{\mathrm{a}}$ & $5.0 \pm 0.9^{\mathrm{a}}$ \\
Node number/plant & $24.6 \pm 1.1^{\mathrm{a}}$ & $24.7 \pm 1.1^{\mathrm{a}}$ & $23.7 \pm 2.7^{\mathrm{a}}$ & $24.3 \pm 2.0^{\mathrm{a}}$ & $23.2 \pm 1.6^{\mathrm{a}}$ & $22.7 \pm 2 .^{\mathrm{a}}$ \\
Pod number/plant & $175 \pm 24^{\mathrm{ab}}$ & $197 \pm 40^{\mathrm{ab}}$ & $195 \pm 18^{\mathrm{ab}}$ & $174 \pm 28^{\mathrm{ab}}$ & $200 \pm 56^{\mathrm{a}}$ & $166 \pm 34^{\mathrm{ab}}$ \\
Seed number/plant & $425 \pm 62^{\mathrm{a}}$ & $423 \pm 78^{\mathrm{a}}$ & $435 \pm 45^{\mathrm{a}}$ & $417 \pm 69^{\mathrm{a}}$ & $441 \pm 175^{\mathrm{a}}$ & $406 \pm 93^{\mathrm{a}}$ \\
Seed weight (g)/plant & $49.6 \pm 12.1^{\mathrm{b}}$ & $47.7 \pm 14.2^{\mathrm{b}}$ & $59.5 \pm 6.5^{\mathrm{a}}$ & $56.7 \pm 8.2^{\mathrm{a}}$ & $58.5 \pm 23.0^{\mathrm{a}}$ & $53.7 \pm 12.4^{\mathrm{a}}$ \\
100 seed weight (g) & $14.0 \pm 0.5^{\mathrm{b}}$ & $13.6 \pm 1.6^{\mathrm{b}}$ & $16.4 \pm 0.8^{\mathrm{a}}$ & $17.4 \pm 1.8^{\mathrm{a}}$ & $16.8 \pm 1.7^{\mathrm{a}}$ & $16.7 \pm 1.0^{\mathrm{a}}$ \\
10 seed length (cm) & $7.20 \pm 0.07^{\mathrm{c}}$ & $7.14 \pm 0.11^{\mathrm{c}}$ & $8.02 \pm 0.08^{\mathrm{a}}$ & $7.72 \pm 0.08^{\mathrm{b}}$ & $7.71 \pm 0.08^{\mathrm{b}}$ & $7.80 \pm 0.09^{\mathrm{b}}$ \\
10 seed width (cm) & $6.28 \pm 0.13^{\mathrm{c}}$ & $6.36 \pm 0.11^{\mathrm{c}}$ & $7.26 \pm 0.05^{\mathrm{a}}$ & $6.90 \pm 0.07^{\mathrm{b}}$ & $7.02 \pm 0.08^{\mathrm{b}}$ & $6.95 \pm 0.10^{\mathrm{b}}$ \\
\hline
\end{tabular}

Data are given as means $\pm S D(n=6)$. Different letters indicate significant differences (LSD test, $P<0.05)$. 
analyzed to count the number per $0.1 \mathrm{~mm}^{2}$ area and determine aperture using the microscope software (NIS elements) measurement tool. A microscopic ruler was used for the size calibration.

\section{Determining $\mathrm{Na}^{+}$concentration}

Leaves and root from 17-day old transgenic lines and WT were sampled and dried at $80^{\circ} \mathrm{C}$ for 3 days. $50 \mathrm{mg}$ of the material was weighed and dissolved with $3 \mathrm{ml}$ of nitric acid and $2 \mathrm{ml}$ of $\mathrm{H}_{2} \mathrm{O}_{2}$ (30\%). The digested samples were diluted to a total volume of $50 \mathrm{ml}$ with ultrapure water and transferred into new tubes before analysis by using an inductively coupled plasma-mass spectrometer (ICP-MS, ELAN DRC-e).

To analyze the relative $\mathrm{Na}^{+}$exclusion, Ten-day-old WT and GmPIP1;6-Oe transgenic soybean plants in hydroponics were treated with $100 \mathrm{mM} \mathrm{NaCl}$ for 7 days. Soybean plants after treatment were transferred into narrow neck flask individually, which filled with same volume of normal nutrient solution, and cultured for 24 hours. $\mathrm{Na}^{+}$concentration of solution was measured by ICP-MS described above. The relative $\mathrm{Na}^{+}$exclusion was calculated by the formula: relative $\mathrm{Na}^{+}$exclusion $=\left(\mathrm{Na}^{+}\right.$concentration of solution $\times$ Volume of solution $) /\left(\mathrm{Na}^{+}\right.$concentration of shoot $\times$ DW of shoot).

\section{Root hydraulic conductance}

Root hydraulic conductance were measured with a hydraulic conductance flow meter (HCFM) (Dynamax, Houston, TX, USA) as described in Vandeleur [23]. 5week-old potted soybean plants grown in greenhouse. 1 day before root hydraulic conductance were measured, control plants were irrigated with normal nutrient solution and treatment plants were irrigated with nutrient solution containing $50 \mathrm{mM} \mathrm{NaCl}$. Measurements were made between 10:00 AM to 12:00 AM. Hydraulic conductance $\left(L_{\mathrm{o}}\right)$ was normalized by dividing total root dry weight. The soil was washed from the roots, and baked at $80^{\circ} \mathrm{C}$ for 3 days.

\section{Additional files}

Additional file 1: Figure S1. Phylogenetic analysis of GmPIP1s and other AQPs by MEGA 5.04. Figure S2. Expression pattern of GMPIP1;6 under $\mathrm{NaCl}$ treatment in leaves relative to control.. Ten-day-old soybean seedlings were treated with or without $100 \mathrm{mM} \mathrm{NaCl}$ in nutrient solution. RNA was extracted from the leaves of these seedlings at 6 hours, 12 hours, 1 day, 3 days, 5 days after treatment. All data are means of four biological replicates with error bars indicating SD. Expression level of treated plants was relative to control plants at each time point. Figure S3. Detection of transgenic soybean with herbicide Liberty. One half of the leaf was painted with $135 \mathrm{mg} / \mathrm{L}$ Liberty ${ }^{\circledR}$, the bar-containing positive transgenic soybean leaves were green and the negative ones were yellow and wilted. Treated leaves were labeled with marker pen which can be seen in the images. Figure S4. Measurement of stomata aperture water loss rate. Ten-day-old WT and GMPIP1;6 overexpression plants in nutrient solution were treated with or without $100 \mathrm{mM} \mathrm{NaCl}$ for
3 days. Leaves were sampled at 2:00 PM to observe the abaxial leaf surface with microscope and measured stomata aperture. Bar $=100 \mathrm{~nm}$. Figure S5. Distribution of intracellular $\mathrm{Na}^{+}$in WT and transgenic soybean plants. Ten-day-old WT and GMPIP1;6 overexpression plants in nutrient solution were treated with or without $100 \mathrm{mM} \mathrm{NaCl}$ for 2 days. Samples of leaves were sliced and stained with CoroNa-Green at 2:00 PM and observed with a confocal microscope. Bar $=100 \mu \mathrm{m}$. Figure S6.

Phenotypic characterization of GMPIP1;6 overexpressing soybean seeds. Mature dried seeds from WT and GMPIP1;6-Oe transgenic soybean plants were recorded. Bar $=3 \mathrm{~cm}$.

Additional file 2: Table S1. Primers used in this study.

\section{Competing interests}

The authors declare that they have no competing interests.

\section{Authors' contributions}

$\mathrm{HS}$ and ST conceived and designed the research. $\mathrm{LZ}, \mathrm{CW}, \mathrm{RL}, \mathrm{RV}, \mathrm{JD}$ and $\mathrm{QH}$ conducted the experiments and analyzed the data. LZ, JD and CW wrote the manuscript. All authors read and approved the manuscript.

\section{Acknowledgments}

This work was supported by National Science Foundation of China (31172024, 31201675), the Ministry of Science and Technology of China (2011CB100303, 2011ZX08004, 2014ZX0800401B) and the Australian Research Council.

\section{Author details}

'State Key Laboratory of Plant Physiology and Biochemistry, College of Life Sciences, Zhejiang University, Hangzhou 310058, P. R. China. ${ }^{2}$ Present Address: College of Agriculture and Biotechnology, Southwest University, 400715 Chongqing, P. R. China. ${ }^{3}$ Australian Research Council Centre of Excellence in Plant Energy Biology, School of Agriculture, Food and Wine, Waite Research Institute, University of Adelaide, PMB1, Glen Osmond, SA 5064, Australia.

Received: 12 May 2014 Accepted: 30 June 2014

Published: 7 July 2014

\section{References}

1. Munns R, Tester M: Mechanisms of salinity tolerance. Annu Rev Plant Biol 2008, 59:651-681.

2. Munns R: Genes and salt tolerance: bringing them together. New Phytol 2005, 167(3):645-663.

3. Colmer TD, Munns R, Flowers TJ: Improving salt tolerance of wheat and barley: future prospects. Aust J Exp Agri 2005, 45(11):1425-1443.

4. Tyerman SD, Skerrett IM: Root ion channels and salinity. Sci Hortic 1999, 78:175-235

5. Teakle NL, Tyerman SD: Mechanisms of $\mathrm{Cl}(-)$ transport contributing to salt tolerance. Plant Cell Environ 2010, 33(4):566-589.

6. Horie T, Schroeder J: Sodium transporters in plants. Diverse genes and physiological functions. Plant Physiol 2004, 136(1):2457-2462.

7. Tester M, Davenport $\mathrm{R}: \mathrm{Na}+$ tolerance and $\mathrm{Na}+$ transport in higher plants. Ann Bot 2003, 91(5):503-527.

8. Chaumont F, Tyerman SD: Aquaporins: highly regulated channels controlling plant water relations. Plant Physiol 2014, 164(4):1600-1618.

9. Steudle E: Water uptake by plant roots: an integration of views. Plant Soil 2000, 226(1):45-56.

10. Krishnamurthy P, Ranathunge K, Franke R, Prakash HS, Schreiber L, Mathew MK: The role of root apoplastic transport barriers in salt tolerance of rice (Oryza sativa L.). Planta 2009, 230(1):119-134.

11. Hose E, Clarkson DT, Steudle E, Schreiber L, Hartung W: The exodermis: a variable apoplastic barrier. J Exp Bot 2001, 52(365):2245-2264.

12. Steudle E: Water uptake by roots: effects of water deficit. J Exp Bot 2000, 51(350):1531-1542.

13. Knepper MA: The aquaporin family of molecular water channels. Proc Natl Acad Sci U S A 1994, 91(14):6255-6258.

14. Tyerman SD, Niemieta CM, Bramley H: Plant aquaporins: multifunctional water and solute channels with expanding roles. Plant Cell Environ 2002, 25:173-194. 
15. Maurel C: Plant aquaporins: novel functions and regulation properties. FEBS Lett 2007, 581(12):2227-2236.

16. Kaldenhoff R, Ribas-Carbo M, Sans JF, Lovisolo C, Heckwolf M, Uehlein N: Aquaporins and plant water balance. Plant Cell Environ 2008, 31(5):658-666

17. Sade N, Gebretsadik M, Seligmann R, Schwartz A, Wallach R, Moshelion M: The role of tobacco Aquaporin1 in improving water use efficiency, hydraulic conductivity, and yield production under salt stress. Plant Physiol 2010, 152(1):245-254

18. Maurel C, Verdoucq L, Luu DT, Santoni V: Plant aquaporins: membrane channels with multiple integrated functions. Annu Rev Plant Biol 2008, 59:595-624.

19. Hachez C, Besserer A, Chevalier AS, Chaumont F: Insights into plant plasma membrane aquaporin trafficking. Trends Plant Sci 2013, 18(6):344-352.

20. Fetter $\mathrm{K}$, Van Wilder V, Moshelion M, Chaumont F: Interactions between plasma membrane aquaporins modulate their water channel activity. Plant Cell 2004, 16(1):215-228.

21. Zelazny E, Borst JW, Muylaert M, Batoko H, Hemminga MA, Chaumont F: FRET imaging in living maize cells reveals that plasma membrane aquaporins interact to regulate their subcellular localization. Proc Nat Acad Sci U S A 2007, 104(30):12359-12364.

22. Temmei Y, Uchida S, Hoshino D, Kanzawa N, Kuwahara M, Sasaki S, Tsuchiya T: Water channel activities of Mimosa pudica plasma membrane intrinsic proteins are regulated by direct interaction and phosphorylation. FEBS Lett 2005, 579(20):4417-4422.

23. Vandeleur RK, Mayo G, Shelden MC, Gilliham M, Kaiser BN, Tyerman SD: The role of plasma membrane intrinsic protein aquaporins in water transport through roots: diurnal and drought stress responses reveal different strategies between isohydric and anisohydric cultivars of grapevine. Plant Physiol 2009, 149(1):445-460.

24. Alleva K, Marquez M, Villarreal N, Mut P, Bustamante C, Bellati J, Martinez G, Civello M, Amodeo G: Cloning, functional characterization, and coexpression studies of a novel aquaporin (FaPIP2;1) of strawberry fruit. J Exp Bot 2010, 61(14):3935-3945.

25. Bellati J, Alleva K, Soto G, Vitali V, Jozefkowicz C, Amodeo G: Intracellular $\mathrm{pH}$ sensing is altered by plasma membrane PIP aquaporin coexpression. Plant Mol Biol 2010, 74(1-2):105-118.

26. Chen W, Yin X, Wang L, Tian J, Yang R, Liu D, Yu Z, Ma N, Gao J: Involvement of rose aquaporin RhPIP1;1 in ethylene-regulated petal expansion through interaction with RhPIP2;1. Plant Mol Biol 2013, 83(3):219-233.

27. Yaneff A, Sigaut L, Marquez M, Alleva K, Pietrasanta LI, Amodeo G: Heteromerization of PIP aquaporins affects their intrinsic permeability. Proc Natl Acad Sci U S A 2014, 111(1):231-236.

28. Johanson U, Karlsson M, Johansson I, Gustavsson S, Sjovall S, Fraysse L, Weig AR, Kjellbom P: The complete set of genes encoding major intrinsic proteins in Arabidopsis provides a framework for a new nomenclature for major intrinsic proteins in plants. Plant Physiol 2001, 126(4):1358-1369.

29. Sakurai J, Ishikawa F, Yamaguchi T, Uemura M, Maeshima M: Identification of 33 rice aquaporin genes and analysis of their expression and function. Plant Cell Physiol 2005, 46(9):1568-1577.

30. Zhang DY, Ali Z, Wang CB, Xu L, Yi JX, Xu ZL, Liu XQ, He XL, Huang YH, Khan IA, Trethowan RM, Ma HX: Genome-wide sequence characterization and expression analysis of major intrinsic proteins in soybean (Glycine max L.). PLoS One 2013, 8(2):e56312.

31. Maurel C, Javot H, Lauvergeat V, Gerbeau P, Tournaire C, Santoni V, Heyes J: Molecular physiology of aquaporins in plants. Int Rev Cytol 2002 215:105-148.

32. Fricke W, Chaumont F: Solute and Water Relations of Growing Plant Cells. In The Expanding Cell, Volume 6. Edited by Verbelen JP, Vissenberg K. Berlin Heidelberg: Springer; 2007:7-31.

33. Liu D, Tu L, Wang L, Li Y, Zhu L, Zhang X: Characterization and expression of plasma and tonoplast membrane aquaporins in elongating cotton fibers. Plant Cell Rep 2008, 27(8):1385-1394.

34. Ma N, Xue J, Li Y, Liu X, Dai F, Jia W, Luo Y, Gao J: Rh-PIP2;1, a rose aquaporin gene, is involved in ethylene-regulated petal expansion. Plant Physiol 2008, 148(2):894-907.

35. Peret B, Li G, Zhao J, Band LR, Voss U, Postaire O, Luu DT, Da Ines O, Casimiro I, Lucas M, Wells DM, Lazzerini L, Nacry P, King JR, Jensen OE, Schaffner AR, Maurel C, Bennett MJ: Auxin regulates aquaporin function to facilitate lateral root emergence. Nat Cell Biol 2012, 14(10):991-998.
36. Aroca R, Porcel R, Ruiz-Lozano JM: Regulation of root water uptake under abiotic stress conditions. J Exp Bot 2012, 63(1):43-57.

37. Hu W, Yuan $Q$, Wang $Y$, Cai R, Deng X, Wang J, Zhou S, Chen M, Chen L, Huang C, Ma Z, Yang G, He G: Overexpression of a wheat aquaporin gene, TaAQP8, enhances salt stress tolerance in transgenic tobacco. Plant Cell Physiol 2012, 53(12):2127-2141.

38. Zhou S, Hu W, Deng X, Ma Z, Chen L, Huang C, Wang C, Wang J, He Y, Yang G, He G: Overexpression of the wheat aquaporin gene, TaAQP7, enhances drought tolerance in transgenic tobacco. PLoS One 2012, 7(12):e52439.

39. Gao Z, He X, Zhao B, Zhou C, Liang Y, Ge R, Shen Y, Huang Z: Overexpressing a putative aquaporin gene from wheat, TaNIP, enhances salt tolerance in transgenic Arabidopsis. Plant Cell Physiol 2010, 51(5):767-775.

40. Sreedharan S, Shekhawat UK, Ganapathi TR: Transgenic banana plants overexpressing a native plasma membrane aquaporin MusaPIP1;2 display high tolerance levels to different abiotic stresses. Plant Biotechnol J 2013, 11(8):942-952.

41. Delgado MJ, Ligero F, Lluch C: Effects of salt stress on growth and nitrogen fixation by pea, faba-bean, common bean and soybean plants. Soil Biol Biochem 1994, 26:371-376.

42. Vandeleur RK, Sullivan W, Athman A, Jordans C, Gilliham M, Kaiser BN, Tyerman SD: Rapid shoot-to-root signalling regulates root hydraulic conductance via aquaporins. Plant Cell Environ 2014, 37(2):520-538.

43. Tournaire-Roux C, Sutka M, Javot H, Gout E, Gerbeau P, Luu DT, Bligny R, Maurel $\mathrm{C}$ : Cytosolic $\mathrm{pH}$ regulates root water transport during anoxic stress through gating of aquaporins. Nature 2003, 425(6956):393-397.

44. Siefritz F, Tyree MT, Lovisolo C, Schubert A, Kaldenhoff R: PIP1 plasma membrane aquaporins in tobacco: from cellular effects to function in plants. Plant Cell 2002, 14(4):869-876.

45. Martinez-Ballesta MC, Aparicio F, Pallas V, Martinez V, Carvajal M: Influence of saline stress on root hydraulic conductance and PIP expression in Arabidopsis. J Plant Physiol 2003, 160(6):689-697.

46. Boursiac Y, Chen S, Luu DT, Sorieul M, van den Dries N, Maurel C: Early effects of salinity on water transport in Arabidopsis roots. Molecular and cellular features of aquaporin expression. Plant Physiol 2005, 139(2):790-805.

47. Marulanda A, Azcon R, Chaumont F, Ruiz-Lozano JM, Aroca R: Regulation of plasma membrane aquaporins by inoculation with a Bacillus megaterium strain in maize (Zea mays L.) plants under unstressed and saltstressed conditions. Planta 2010, 232(2):533-543.

48. Muries B, Faize M, Carvajal M, Martinez-Ballesta Mdel C: Identification and differential induction of the expression of aquaporins by salinity in broccoli plants. Mol Biosyst 2011, 7(4):1322-1335.

49. Calvo-Polanco M, Sanchez-Romera B, Aroca R: Mild salt stress conditions induce different responses in root hydraulic conductivity of phaseolus vulgaris over-time. PLoS One 2014, 9(3):e90631.

50. Liu C, Fukumoto T, Matsumoto T, Gena P, Frascaria D, Kaneko T, Katsuhara M, Zhong S, Sun X, Zhu Y, Iwasaki I, Ding X, Calamita G, Kitagawa Y: Aquaporin OsPIP1;1 promotes rice salt resistance and seed germination. Plant Physiol Biochem 2012, 63C:151-158.

51. Durand M, Lacan D: Sodium partitioning within the shoot of soybean. Physiol Plant 1994, 91(1):65-71.

52. Lauchli A: Salt exclusion: An adaptation of legumes for crops and pastures under saline conditions. In Salinity Tolerance in Piants, Strategies for Crop Improvement. Edited by Staples RC, Toenniessen GH. New York: John Wiley \& Sons; 1984:171-187.

53. Lohaus G, Hussmann M, Pennewiss K, Schneider H, Zhu JJ, Sattelmacher B: Solute balance of a maize (Zea mays L.) source leaf as affected by salt treatment with special emphasis on phloem retranslocation and ion leaching. J Exp Bot 2000, 51(351):1721-1732.

54. Li WY, Wong FL, Tsai SN, Phang TH, Shao G, Lam HM: Tonoplast-located $\mathrm{GmCLC1}$ and $\mathrm{GmNHX1}$ from soybean enhance NaCl tolerance in transgenic bright yellow (BY)-2 cells. Plant Cell Environ 2006, 29(6):1122-1137.

55. Uehlein N, Lovisolo C, Siefritz F, Kaldenhoff R: The tobacco aquaporin NtAQP1 is a membrane $\mathrm{CO} 2$ pore with physiological functions. Nature 2003, 425(6959):734-737.

56. Flexas J, Ribas-Carbo M, Hanson DT, Bota J, Otto B, Cifre J, McDowell N, Medrano H, Kaldenhoff R: Tobacco aquaporin NtAQP1 is involved in mesophyll conductance to CO2 in vivo. Plant J 2006, 48(3):427-439.

57. Heckwolf M, Pater D, Hanson DT, Kaldenhoff R: The Arabidopsis thaliana aquaporin AtPIP1;2 is a physiologically relevant $\mathrm{CO}(2)$ transport facilitator. Plant J 2011, 67(5):795-804. 
58. Uehlein $N$, Sperling $H$, Heckwolf M, Kaldenhoff R: The Arabidopsis aquaporin PIP1;2 rules cellular $\mathrm{CO}(2)$ uptake. Plant Cell Environ 2012, 35(6):1077-1083.

59. Evans JR, Kaldenhoff R, Genty B, Terashima I: Resistances along the $\mathrm{CO} 2$ diffusion pathway inside leaves. J Exp Bot 2009, 60(8):2235-2248.

60. Patrick JW, Zhang W, Tyerman SD, Offler CE, Walker NA: Role of membrane transport in phloem translocation of assimilates and water. Func Plant Biol 2001, 28(7):697-709.

61. Song ZY, Tian JL, Fu WZ, Li L, Lu LH, Zhou L, Shan ZH, Tang GX, Shou HX: Screening Chinese soybean genotypes for Agrobacterium-mediated genetic transformation suitability. J Zhejiang Univ Sci B 2013, 14(4):289-298

doi:10.1186/1471-2229-14-181

Cite this article as: Zhou et al:: Constitutive overexpression of soybean plasma membrane intrinsic protein GmPIP1;6 confers salt tolerance. BMC Plant Biology 2014 14:181.

Submit your next manuscript to BioMed Central and take full advantage of:

- Convenient online submission

- Thorough peer review

- No space constraints or color figure charges

- Immediate publication on acceptance

- Inclusion in PubMed, CAS, Scopus and Google Scholar

- Research which is freely available for redistribution
( Biomed Central 